\title{
Effect of ketoconazole on the pharmacokinetics of rosiglitazone in healthy subjects
}

\author{
Ji-Young Park, Kyoung-Ah Kim, Jae-Gook Shin \& Ki Young Lee \\ Department of Pharmacology and Department of Endocrinology, Gachon Medical School and Clinical Trial Centre, Gil Medical Centre, \\ Incheon, and Department of Pharmacology, College of Medicine, Inje University, Busan, Korea
}

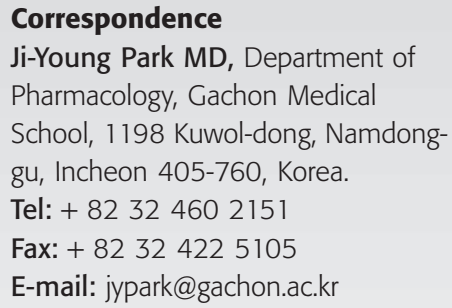

\section{Keywords}

CYP2C8, drug interaction, ketoconazole, pharmacokinetics, rosiglitazone

\section{Received}

21 January 2004

Accepted

30 March 2004

\begin{abstract}
Aims
Fungal infection is a significant comorbidity in patients with diabetes mellitus, and ketoconazole, an antifungal agent, causes a number of drug interactions with coadministered drugs. Rosiglitazone is a novel thiazolidinedione antidiabetic drug, mainly metabolized by CYP2C8 and to a lesser extent CYP2C9. We investigated the possible effect of ketoconazole on the pharmacokinetics of rosiglitazone in humans.

\section{Methods}

Ten healthy Korean male volunteers were treated twice daily for 5 days with $200 \mathrm{mg}$ ketoconazole or with placebo, using a randomized, open-label, two-way crossover study. On day 5, a single dose of $8 \mathrm{mg}$ rosiglitazone was administered orally, and plasma rosiglitazone concentrations were measured.

\section{Results}

Ketoconazole increased the mean area under the plasma concentration-time curve for rosiglitazone by $47 \%[P=0.0003 ; 95 \%$ confidence interval $(\mathrm{Cl}) 23,70]$ and the mean elimination half-life from 3.55 to $5.50 \mathrm{~h}(P=0.0003 ; 95 \% \mathrm{Cl}$ in difference $1.1,2.4)$. The peak plasma concentration of rosiglitazone was increased by ketoconazole treatment by $17 \%(P=0.03 ; 95 \% \mathrm{Cl} 5,29)$. The apparent oral clearance of rosiglitazone decreased by $28 \%$ after ketoconazole treatment $(P=0.0005 ; 95 \% \mathrm{Cl}$ 18, 38).
\end{abstract}

\section{Conclusions}

This study revealed that ketoconazole affected the disposition of rosiglitazone in humans, probably by the inhibition of CYP2C8 and CYP2C9, leading to increasing rosiglitazone concentrations that could increase the efficacy of rosiglitazone or its adverse events.

\section{Introduction}

Rosiglitazone is a novel insulin-sensitizing, oral antidiabetic agent of the thiazolidinedione class, used in the treatment of patients with Type 2 diabetes mellitus, and is an effective and well-tolerated agent for lowering blood glucose [1, 2]. It improves insulin sensitivity through the activation of the nuclear receptors, peroxisome proliferator-activating receptor gamma (PPAR $\gamma$ ) [3]. It is rapidly and completely absorbed, with absolute bioavailability estimated to be over $99 \%$ following oral administration [4]. It is metabolized through $\mathrm{N}$ demethylation and $p$-hydroxylation, mainly by CYP2C8 and to a lesser extent CYP2C9 [5], and does not undergo enterohepatic recirculation $[5,6]$.

Ketoconazole, an imidazole antifungal agent, is an effective drug for treating fungal infections [7]. It is a potent inhibitor of cytochrome $\mathrm{P} 450$ isoforms in vitro and in vivo, which results in many clinically signifi- 
cant drug interactions with coadministered drugs $[8$, 9].

Type 2 diabetes mellitus is a common progressive disease affecting $1-4 \%$ of the population that leads to significantly increased comorbidity [10]. In addition to antidiabetic drugs, many other drugs may be prescribed to treat comorbidities in diabetic patients, which may result in drug interactions. It has been reported that systemic antifungal agents have been used in $3.0 \%$ of patients with Type 2 diabetes mellitus [10].

As ketoconazole could be prescribed to treat fungal infection in patients also receiving rosiglitazone, there might be potential for a deleterious drug interaction. In addition, it has been reported that ketoconazole had a comparable inhibitory effect on CYP2C8-catalysed paclitaxel $6 \alpha$-hydroxylation to that of quercetin, a selective potent inhibitor of CYP2C8 [11]. Furthermore, ketoconazole showed a potent inhibitory effect on CYP2C8-catalysed torsemide metabolism in vitro [12]. These results suggest that ketoconazole may act as an inhibitor of CYP2C8 in addition to CYP3A4. By contrast, another in-vitro study showed little inhibition of rosiglitazone metabolism by ketoconazole, but concentrations of ketoconazole were far lower than therapeutic concentrations. There have been no data in humans investigating a drug interaction between ketoconazole and rosiglitazone.

The aim of the present study was to evaluate possible effects of ketoconazole on the pharmacokinetics of rosiglitazone in healthy volunteers.

\section{Methods}

Subjects

Ten healthy Korean men (age 22-34 years; weight 63$75 \mathrm{~kg}$ ) participated in the study after they had given written informed consent. The volunteers were confirmed as healthy by medical history, physical examination, and routine laboratory tests before they were enrolled in the study.

\section{Study design}

The study protocol was approved by the Institutional Review Board of Gil Medical Centre, Gachon Medical School, Incheon, Korea. A randomized, open-label, twoway crossover study was performed. The study phases were separated by a 4-week washout period, and the general study design was identical in both phases. The volunteers were given either $200 \mathrm{mg}$ ketoconazole (Kun Wha Pharmaceutical Co., Seoul, Korea) or matched placebo orally twice daily for 5 days at $08.00 \mathrm{~h}$ and $20.00 \mathrm{~h}$ and the order of administration of two drugs was determined by the randomization schedule generated prior to the start of the study. On the morning of day 5 , a single oral dose of $8 \mathrm{mg}$ rosiglitazone (Avandia ${ }^{\circledR}$; GlaxoSmithKline Korea, Seoul, Korea) was administered with water at $09.00 \mathrm{~h}$. An interval of $1 \mathrm{~h}$ between the ingestion of ketoconazole and rosiglitazone was chosen to allow disintegration and dissolution of the ketoconazole tablet before the administration of rosiglitazone. The drugs used in this study were given in a sitting position, and the subjects remained seated for the next $3 \mathrm{~h}$ after administration of rosiglitazone. A standard light meal was given after $4 \mathrm{~h}$. The subjects were under direct medical supervision throughout the day of rosiglitazone treatment.

\section{Sample preparations}

Blood samples were drawn immediately before and at $0.5,1,1.5,2,2.5,3,4,5,6,8,10,12$ and $14 \mathrm{~h}$ after the administration of rosiglitazone. Blood samples, collected in heparinized glass tubes (Vacutainer ${ }^{\circledR}$; Becton Dickinson, Franklin Lakes, NJ, USA), were centrifuged ( $209 \mathrm{~g}$ ) for $15 \mathrm{~min}$, and the separated plasma samples stored at $-80{ }^{\circ} \mathrm{C}$ until assay.

Plasma rosiglitazone concentrations were quantified using high-performance liquid chromatography with a fluorescence detector described previously [13]. The limit of quantification for rosiglitazone was $5 \mathrm{ng} \mathrm{ml}^{-1}$ using a $0.2-\mathrm{ml}$ plasma sample volume. The precision and accuracy for the quality controls were high, with a coefficient of variation of $<8 \%$ within runs (intraday) and between runs (interdays).

\section{Pharmacokinetic calculations}

The pharmacokinetic parameters of rosiglitazone were estimated by noncompartmental methods, using WinNonlin ${ }^{\circledR}$ V2.0 (Scientific Consulting Inc, Apex, NC, USA). The elimination rate constant $\left(k_{\mathrm{e}}\right)$ was determined by linear regression analysis of the log-linear part of the plasma concentration-time curve. The total area under the plasma concentration-time curve (AUC) was calculated using the linear trapezoidal rule. The AUC from 0 to infinity $[\operatorname{AUC}(0, \infty)]$ was calculated as $\operatorname{AUC}(0, \infty)=$ $\mathrm{AUC}+C_{\mathrm{t}} / k_{\mathrm{e}}$ (where $C_{\mathrm{t}}$ was the last plasma concentration measured). The half-life $\left(t_{1 / 2}\right)$ of rosiglitazone was calculated using: $t_{1 / 2}=\ln 2 / k_{\mathrm{e}}$. The apparent oral clearance $(\mathrm{CL} / \mathrm{F})$ of rosiglitazone was calculated as $\mathrm{CL} / \mathrm{F}=$ dose/ $\operatorname{AUC}(0, \infty)$. The maximum plasma concentration $\left(C_{\max }\right)$ and the time to reach $C_{\max }\left(t_{\max }\right)$ were estimated directly from the observed plasma concentration-time data.

\section{Statistical analysis}

The results are expressed as means \pm standard deviations. The pharmacokinetic parameters of rosiglitazone 


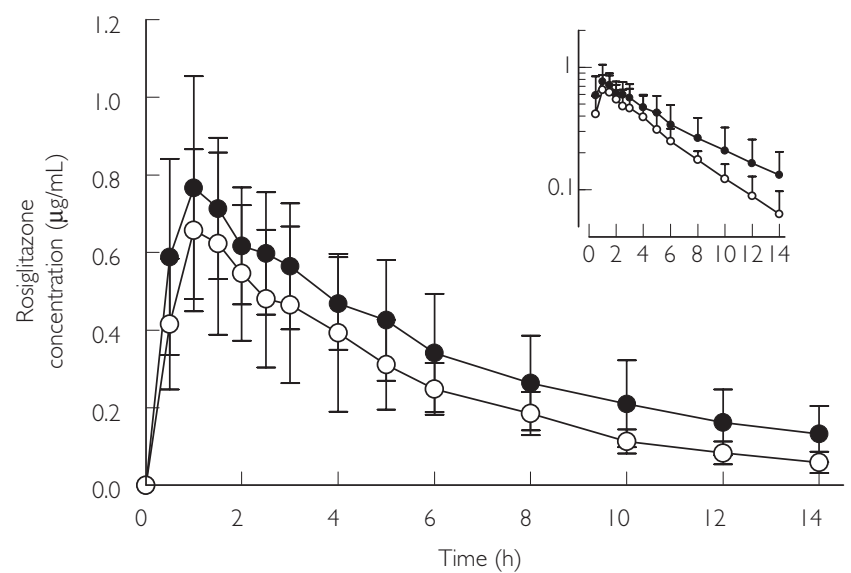

Figure 1

Mean plasma concentrations of rosiglitazone in 10 healthy subjects after a single oral dose of $8 \mathrm{mg}$ rosiglitazone following a 5-day pretreatment with placebo or ketoconazole twice daily. Rosiglitazone in the placebo phase $(\bigcirc)$; rosiglitazone in the ketoconazole phase $(\mathbf{)})$. Variability is shown as SD. Inset: semilogarithmic scale

were compared between the two phases with a paired $t$ test (two-tailed). The $t_{\max }$ data were compared with the Wilcoxon signed-rank test. All the data were analysed with the statistical program Sigmastat ${ }^{\circledR}$ for Windows (version 2.0; SPSS Inc., Chicago, IL, USA). Differences were considered statistically significant at $P<0.05$.

\section{Results}

Ketoconazole increased the plasma concentrations of rosiglitazone (Figure 1). After administration of ketoconazole, the mean $\operatorname{AUC}(0, \infty)$ of rosiglitazone was increased by $47 \%(P=0.0003)$. The elimination halflife of rosiglitazone was lengthened from $3.55 \mathrm{~h}$ to $5.50 \mathrm{~h}(P=0.0003)$ and $C_{\max }$ was also increased by $17 \%$ $(P=0.03$; Table 1$)$. The $\mathrm{CL} / \mathrm{F}$ decreased about $30 \%$ after ketoconazole treatment compared with placebo treatment $(P=0.0005)$. The decrease in $\mathrm{CL} / \mathrm{F}$ and the increases in $t_{1 / 2}$ and AUC after the ketoconazole treatment were observed in every subject (Figure 2).

\section{Discussion}

Ketoconazole increased the AUC of rosiglitazone by $47 \%$ and decreased its oral clearance by $28 \%$ compared with placebo treatment. Theoretically, the potential for a drug interaction between two drugs may be low, because established data show that rosiglitazone is metabolized mainly by CYP2C8 and to a lesser extent CYP2C9 $[4,5]$ whereas ketoconazole is a potent inhibitor of CYP3A4 $[8,9]$. In addition, it has been reported that the pharmacokinetics of rosiglitazone are unaf-
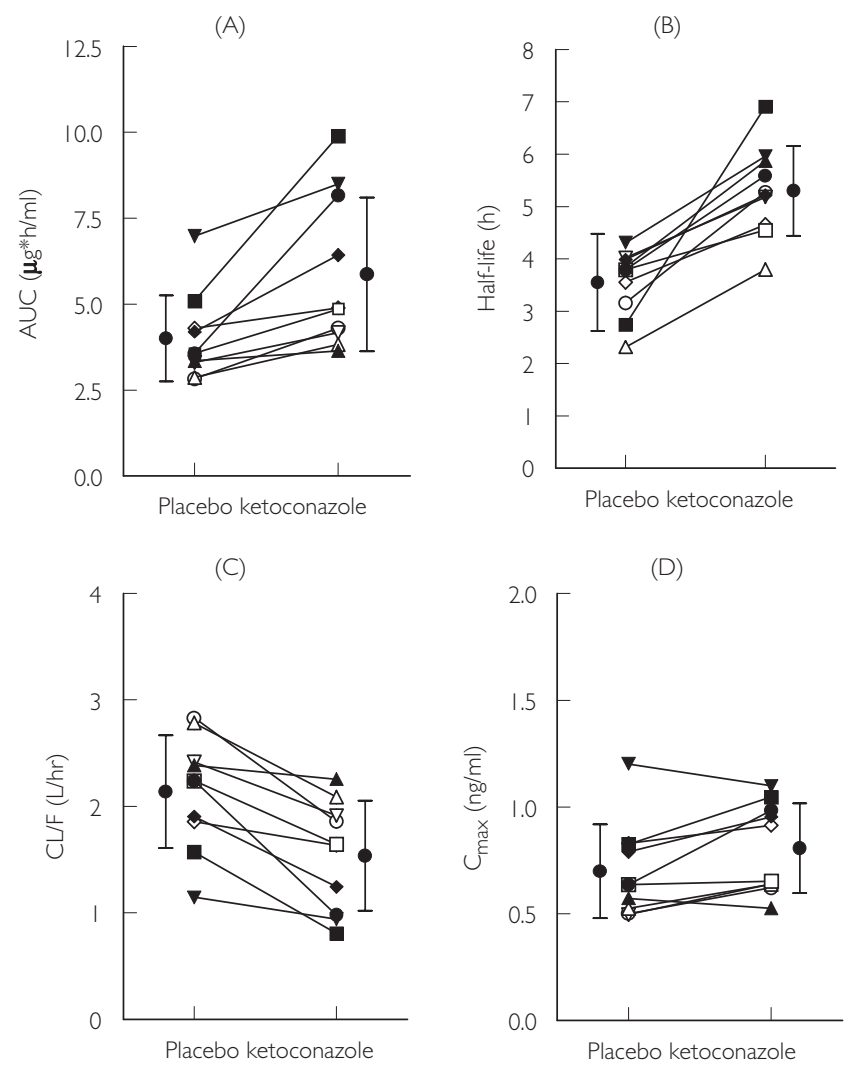

Figure 2

Individual total area under the concentration-time curve $[\operatorname{AUC}(0, \infty)](A)$, elimination half-life (B), oral clearance $(\mathrm{CL} / \mathrm{F})(\mathrm{C})$, peak plasma concentration $\left(C_{\max }\right)(D)$ values for rosiglitazone in 10 healthy subjects after a 5-day pretreatment with placebo or ketoconazole twice daily

fected by the various coadministered drugs [14-16]. By contrast, recently it has been reported that the pharmacokinetics of rosiglitazone are affected by the coadministered drugs $[13,17]$.

Considering the significant effect of ketoconazole on the pharmacokinetics of rosiglitazone in the present study, it is reasonable to postulate that ketoconazole may inhibit cytochrome P450 isoforms other than CYP3A4. Although ketoconazole is a potent inhibitor of CYP3A4 [9], some reports have shown that drugs that are not metabolized by CYP3A4 may be subject to drug interactions with ketoconazole [8, 9, 18]. In recent in-vitro studies, ketoconazole potently inhibited CYP2C8-catalysed paclitaxel and torsemide metabolisms [inhibitory constant $\left(K_{\mathrm{i}}\right) \quad 2.5 \mu \mathrm{mol} \mathrm{l}^{-1}$ and $11.8 \mu \mathrm{mol} \mathrm{l}^{-1}$, respectively] [11, 12]. However, Baldwin et al. [5] showed ketoconazole did not inhibit rosiglitazone metabolism in vitro but using a concentration of ketoconazole $(1 \mu \mathrm{M})$ far lower than usual therapeutic concentrations (5-20 $\mu \mathrm{M}$ for $200-400 \mathrm{mg}$ daily) [7]. 
Table 1

Pharmacokinetic parameters of rosiglitazone in 10 healthy male Korean subjects after a single oral administration of $8 \mathrm{mg}$ rosiglitazone following pretreatment with placebo or $200 \mathrm{mg}$ ketoconazole twice daily for 5 days

\begin{tabular}{|c|c|c|c|c|}
\hline Variable & $\begin{array}{l}\text { Placebo phase } \\
\text { (control) }\end{array}$ & $\begin{array}{l}\text { Ketoconazole } \\
\text { phase }\end{array}$ & $\begin{array}{l}\text { Mean difference between } \\
\text { placebo and ketoconazole } \\
(95 \% \mathrm{Cl})\end{array}$ & P-value \\
\hline$C_{\max }\left(\mu g \mathrm{ml}^{-1}\right)$ & $0.70 \pm 0.22$ & $0.81 \pm 0.21^{*}$ & $0.11(0.01,0.20)$ & 0.03 \\
\hline Percentage of control (range) & $100 \%$ & $117 \%(91-155 \%)$ & $117 \%(105,129)$ & \\
\hline Half-life (h) & $3.55 \pm 0.63$ & $5.50 \pm 1.35 \ddagger$ & $1.75(1.1,2.4)$ & 0.0003 \\
\hline Percentage of control (range) & $100 \%$ & $153 \%(120-252 \%)$ & $153 \%(130,177)$ & \\
\hline$C L / F\left(\mid h^{-1}\right)$ & $2.14 \pm 0.53$ & $1.53 \pm 0.53 \ddagger$ & $-0.6(-0.35,-0.86)$ & 0.0005 \\
\hline Percentage of control (range) & $100 \%$ & $72 \%(44-95 \%)$ & $72 \%(62,82)$ & \\
\hline $\operatorname{A\cup C}(0,14)\left(\mu \mathrm{g} \mathrm{hm} \mathrm{^{-1 } )}\right.$ & $3.69 \pm 1.11$ & $4.87 \pm 1.60 \dagger$ & $1.18(0.42,1.94)$ & 0.007 \\
\hline Percentage of control (range) & $100 \%$ & $133 \%(105-206 \%)$ & $133 \%(114,151)$ & \\
\hline
\end{tabular}

Data are mean values $\pm S D ; t_{\max }$ data are given as median with range; $C_{\max ,}$ peak plasma concentration; $t_{\max }$ time to peak concentration; $\mathrm{K}_{\mathrm{e}}$ elimination rate constant; $A \cup C$, area under the plasma concentration-time curve. ${ }^{*} \mathrm{P}<0.05$ versus control; $\mathrm{tP}<0.01$ versus control; $\mathrm{P}<0.001$ versus control.

Although we did not determine the concentrations of ketoconazole, our results indicate that currently used doses of ketoconazole cause a drug interaction with rosiglitazone, probably by the inhibition of CYP2C8. Because of linear pharmacokinetic characteristics of ketoconazole, lower clinical doses (200 mg daily) may have a lesser effect on the pharmacokinetics of rosiglitazone and larger doses of ketoconazole (800-1600 mg daily) may have a greater effect. Our data suggest that ketoconazole may also cause drug interactions with other important therapeutic drugs mainly catalysed by CYP2C8 [19-22].

It has also been reported that ketoconazole prolongs $t_{1 / 2}$ and increases the AUC of tolbutamide, which is metabolized by CYP2C9 [18]. According to in-vitro studies from our laboratory (K.-A. Kim et al., unpublished data), ketoconazole showed an inhibitory effect on not only CYP2C8-catalysed paclitaxel $6 \alpha-$ hydroxylation but also CYP2C9-catalysed S-warfarin 7-hydroxylation in human liver microsomes. Therefore, theoretically the increase in AUC of rosiglitazone could be mediated via the inhibition of CYP2C8- and CYP2C9-catalysed rosiglitazone metabolism by ketoconazole. Unfortunately, we only determined the concentrations of rosiglitazone up to $14 \mathrm{~h}$ after dosing, so that the $\operatorname{AUC}(0, \infty)$ during ketoconazole treatment may not be accurate. However, considering the increase of around twofold in the concentrations at $14 \mathrm{~h}$ after dosing and a significant decrease in the elimination rate constant, the AUC estimates are probably valid.

Even though genetic polymorphisms of CYP2C8 and CYP2C9 are very rare in Korean populations [23, 24], they may affect plasma concentrations of rosiglitazone and its pharmacokinetics. However, we could find no available data on this.

The oral bioavailability of rosiglitazone in humans is about $99 \%$, so it is not significantly metabolized during the first pass [4]. Even though the change of $C_{\max }$ was significant after ketoconazole treatment, the increase was modest at $17 \%$, and supports negligible first-pass metabolism of rosiglitazone. A previous report showed that gemfibrozil, a potent inhibitor of CYP2C8, affected rosiglitazone pharmacokinetics, with a similar change of $C_{\max }$ as in our results [17].

Clinically, the onset of antihyperglycaemic activity is noted as early as 2 weeks of rosiglitazone therapy, with maximal response at 6 and 12 weeks [25]. Because the blood glucose-lowering effect of rosiglitazone shows dose and concentration dependence at steady state [1, $2,25]$, it is reasonable to assume that coadministration of rosiglitazone and ketoconazole could increase the efficacy. Rosiglitazone therapy does not appear to cause the hepatotoxicity observed with other thiazolidinediones [1, 2, 25-27]. However, symptomatic peripheral 
and pulmonary oedema is quite common and occasionally profound, even presenting as anasarca [28-30]. This has emerged as the most serious adverse event clinically, and there may be higher risk of this and other adverse events during concurrent use of ketoconazole and rosiglitazone [31]. However, there are no available data concerning the relation between the concentration of rosiglitazone and occurrence of oedema clinically.

Pioglitazole is also commercially available from the thiazolidinedione class and is metabolized by CYP3A4 and CYP2C8/9 [32]. Ketoconazole might be expected to cause a significant interaction with pioglitazone. In addition, even though there are no data on the inhibitory effects of other azole antifungal agents on rosiglitazone metabolism, other interactions are possible $[33,34]$.

In conclusion, ketoconazole modestly decreased the oral clearance of rosiglitazone in humans. The mechanism that underlies the interaction between ketoconazole and rosiglitazone probably involves the inhibition of CYP2C8- and CYP2C9-catalysed rosiglitazone metabolism by ketoconazole. Concomitant administration of ketoconazole could thus result in increased plasma concentrations of rosiglitazone with increased efficacy and/or adverse events.

We thank Su-Lyun Kim for technical assistance. This study was supported by a grant fron the Korea Health 21 R\&D Project. Ministry of Health \& Welfare, R. O. K (03-PJ10-PG13-GD01-0002).

\section{References}

1 Malinowski JM, Bolesta S. Rosiglitazone in the treatment of type 2 diabetes mellitus: a critical review. Clin Ther 2000; 22: 1151 68.

2 Balfour JA, Plosker GL. Rosiglitazone. Drugs 1999; 57: 921-30.

3 Lehmann JM, Moore LB, Smith-Oliver TA, Wilkison WO, Willson TM, Kliewer SA. An antidiabetic thiazolidinedione is a high affinity ligand for peroxisome proliferator-activated receptor gamma (PPAR gamma). J Biol Chem 1995; 270: 12953-6.

4 Cox PJ, Ryan DA, Hollis FJ et al. Absorption, disposition, and metabolism of rosiglitazone, a potent thiazolidinedione insulin sensitizer, in humans. Drug Metab Dispos 2000; 28: 772-80.

5 Baldwin SJ, Clarke SE, Chenery RJ. Characterization of the cytochrome $\mathrm{P} 450$ enzymes involved in the in vitro metabolism of rosiglitazone. Br J Clin Pharmacol 1999; 48: 424-32.

6 Bolton GC, Keogh JP, East PD, Hollis FJ, Shore AD. The fate of a thiazolidinedione antidiabetic agent in rat and dog. Xenobiotica 1996; 26: 627-36.

7 Daneshmend TK, Warnock DW. Clinical pharmacokinetics of ketoconazole. Clin Pharmacokinet 1988; 14: 13-34.
8 Lomaestro BM, Piatek MA. Update on drug interactions with azole antifungal agents. Ann Pharmacother 1998; 32: 915-28.

9 Venkatakrishnan K, von Moltke LL, Greenblatt DJ. Effects of the antifungal agents on oxidative drug metabolism: clinical relevance. Clin Pharmacokinet 2000; 38: 111-80.

10 Reunanen A, Kangas T, Martikainen J, Klaukka T. Nationwide survey of comorbidity, use, and costs of all medications in Finnish diabetic individuals. Diabetes Care 2000; 23: 1265-71.

11 Bun SS, Ciccolini J, Bun H, Aubert C, Catalin J. Drug interactions of paclitaxel metabolism in human liver microsomes. J Chemother 2003; 15: 266-74.

12 Ong CE, Coulter S, Birkett DJ, Bhasker CR, Miners JO. The xenobiotic inhibitor profile of cytochrome P4502C8. Br J Clin Pharmacol 2000; 50: 573-80.

13 Park JY, Kim KA, Kang MH, Shin JG. Effect of rifampin on the pharmacokinetics of rosiglitazone in healthy subjects. Clin Pharmacol Ther 2004; 75: 157-62.

14 Miller AK, DiCicco RA, Freed MI. The effect of ranitidine on the pharmacokinetics of rosiglitazone in healthy adult male volunteers. Clin Ther 2002; 24: 1062-71.

15 Miller AK, Inglis AM, Culkin KT, Jorkasky DK, Freed MI. The effect of acarbose on the pharmacokinetics of rosiglitazone. Eur J Clin Pharmacol 2001; 57: 105-9.

16 Rao MN, Mullangi R, Katneni $\mathrm{K}$ et al. Lack of effect of sucralfate on the absorption and pharmacokinetics of rosiglitazone. J Clin Pharmacol 2002; 42: 670-5.

17 Niemi M, Backman JT, Granfors M, Laitila J, Neuvonen M, Neuvonen PJ. Gemfibrozil considerably increases the plasma concentrations of rosiglitazone. Diabetologia 2003; 46: 1319-23.

18 Krishnaiah YS, Satyanarayana S, Visweswaram D. Interaction between tolbutamide and ketoconazole in healthy subjects. Br J Clin Pharmacol 1994; 37: 205-7.

19 Sonnichsen DS, Liu Q, Schuetz EG, Schuetz JD, Pappo A, Relling MV. Variability in human cytochrome $\mathrm{P} 450$ paclitaxel metabolism. J Pharmacol Exp Ther 1995; 275: 566-75.

20 Nadin L, Murray M. Participation of CYP2C8 in retinoic acid 4hydroxylation in human hepatic microsomes. Biochem Pharmacol 1999; 58: 1201-8.

21 Ohyama K, Nakajima M, Nakamura S, Shimada N, Yamazaki H, Yokoi T. A significant role of human cytochrome P450 2C8 in amiodarone N-deethylation: an approach to predict the contribution with relative activity factor. Drug Metab Dispos 2000; 28: 1303-10.

22 Li XQ, Bjorkman A, Andersson TB, Ridderstrom M, Masimirembwa $\mathrm{CM}$. Amodiaquine clearance and its metabolism to $\mathrm{N}$ desethylamodiaquine is mediated by CYP2C8: a new high affinity and turnover enzyme-specific probe substrate. J Pharmacol Exp Ther 2002; 300: 399-407.

23 Yoon YR, Shon JH, Kim MK et al. Frequency of cytochrome P450 2C9 mutant alleles in a Korean population. Br J Clin Pharmacol 2001; 51: 277-80.

24 Cho J, Suh Y, Lee J et al. Identification of polymorphism in human CYP2C8 gene by two-dimensional gel scanning in healthy Koreans. Clin Pharmacol Ther 2003; 73: P41. 
25 Avandia $^{\circledR}$ (GlaxoSmithKline). PDR Electronic Library ${ }^{\text {TM }} 2003$. Montvale, NJ: Thomson Medical Economics, 2003: 1.

26 Watanabe I, Tomita A, Shimizu M et al. A study to survey susceptible genetic factors responsible for troglitazone-associated hepatotoxicity in Japanese patients with type 2 diabetes mellitus. Clin Pharmacol Ther 2003; 73: 435-55.

27 Otto C, Lehrke M, Goke B. Novel insulin sensitizer: pharmacogenomic aspects. Pharmacogenomics 2002; 3: 99116.

28 Kermani A, Garg A. Thiazolidinedione-associated congestive heart failure and pulmonary edema. Mayo Clin Proc 2003; 78: 108891.

29 Niemeyer NV, Janney LM. Thiazolidinedione-induced edema. Pharmacotherapy 2002; 22: 924-9.
30 Thomas ML, Lloyd SJ. Pulmonary edema associated with rosiglitazone and troglitazone. Ann Pharmacother 2001; 35: $123-$ 4.

31 Idris I, Gray S, Donnelly R. Rosiglitazone and pulmonary oedema: an acute dose-dependent effect on human endothelial cell permeability. Diabetologia 2003; 46: 288-90.

32 Eckland DA, Danhof M. Clinical pharmacokinetics of pioglitazone. Exp Clin Endocrinol 2001; 108: S234-S242.

33 Albengres E, Le Louet H, Tillement JP. Systemic antifungal agents. Drug interactions of clinical significance. Drug Saf 1998; 18: 8397.

34 Lomaestro BM, Piatek MA. Update on drug interactions with azole antifungal agents. Ann Pharmacother 1998; 32: 91528. 